\title{
Using a FACTS Device as a Power Conditioner Suitable for Dynamic Reactive Power Compensation in Railway Application
}

\author{
Josip PAVLEKA, Srete NIKOLOVSKI, Anton MARUŠIĆ
}

\begin{abstract}
The paper presents advantages of dynamic reactive power compensation facilities instead of until now used fixed compensation, as a standard technical solution in railway. Short overview of theory in the field of FACTS device is given. Simulations of these systems have been successfully developed in the MATLAB Simulink program. Recommendation is given for some of main parts in plant design. Results of simulation were proven through the measurement, which was done. Finally, the impact of reactive power compensation using FACTS device on the stability of the EPS (Electrical Power System) voltage was evaluated. Significantly, reduced cost has been shown for over-consumed reactive energy.
\end{abstract}

Keywords: cost reduction; FACTS (Flexible AC Transmission System); MATLAB Simulink Model; power conditioning; reactive power compensation; simulation

\section{INTRODUCTION}

Maintaining a balance between consumption and generation of reactive energy has been the subject of numerous scientific papers since the commencement of commercial use of EPS. The challenge is to find the right balance between the minimum reactive energy flow to make the most of the EPS capacity for the transfer of energy and sufficient amount of reactive energy to maintain the desired voltage profile. If an appropriate ratio is found by calculation or measurement, entering a proper amount of reactive energy may prove to be difficult, and in some cases unfeasible.

The Croatian National Electricity Company - Croatian Electricity Company (HEP) does not charge the energy fee for the spent reactive power in households. However, the price of over-consumed reactive energy for legal persons is $0,15 \mathrm{HRK} / \mathrm{kVArh}$ or $0,16 \mathrm{HRK} / \mathrm{kVArh}$, depending on the voltage level [1]. The spent reactive energy is considered excessive if it exceeds $33 \%$ of the energy consumed corresponding to the power factor $\lambda=0,95$.

New technologies have emerged in recent years that address some of the shortcomings of reactive power compensation based on capacitor batteries. Such systems could also be used to obtain reactive energy with less undesirable transient phenomena and independent of voltage. New compensation options have emerged with the emergence of controlled switches and new, increased capabilities of semiconductor power components, [2]. Some of the new reactive power compensation technologies include the Static Synchronous Generator (SSG), Static Var Compensator (SVC), Thyristor-Actuated Chokes and Capacitors (TCR, TSR, TSC), Static VAR (SVS), Active Filters (AF) power supply unit (UPQC), [3].

\section{REACTIVE POWER AND POWER FACTOR}

Reactive energy is one of the most important factors in AC power systems. Employees involved in the maintenance and operation of such systems should keep in mind the importance that reactive energy has in stability of the power system. Reliable and economically acceptable use of electricity therefore depends on the availability of the required capacitive or inductive reactive energy to the system.

The reactive power compensation systems can be divided into passive and active compensation systems. Passive systems differ from those active in that they do not contain elements of power electronics. Passive reactive power compensation systems include inclusive capacitors and chokes.

Active reactive power compensation systems, also known as FACTS (Flexible AC Transmission System), are based on semiconductor elements of power electronics. FACTS devices enable greater controllability and more sophisticated power factor control.

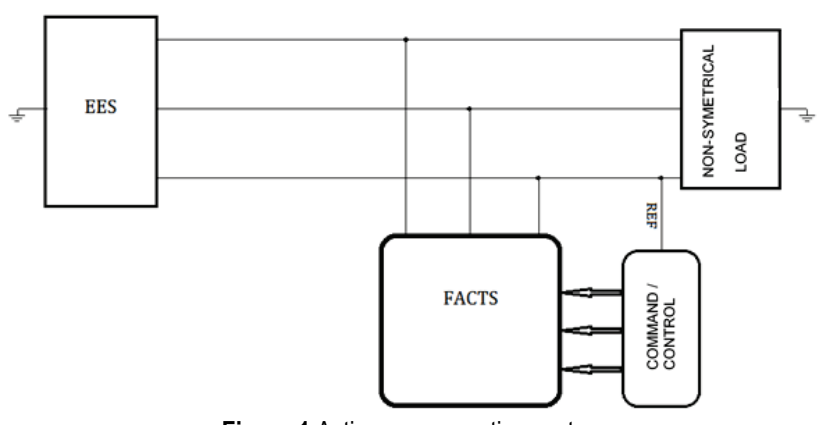

Figure 1 Active compensation system

Greater FACTS handling capability enables reliable compensation at static and dynamic system conditions, thus improving overall system stability.

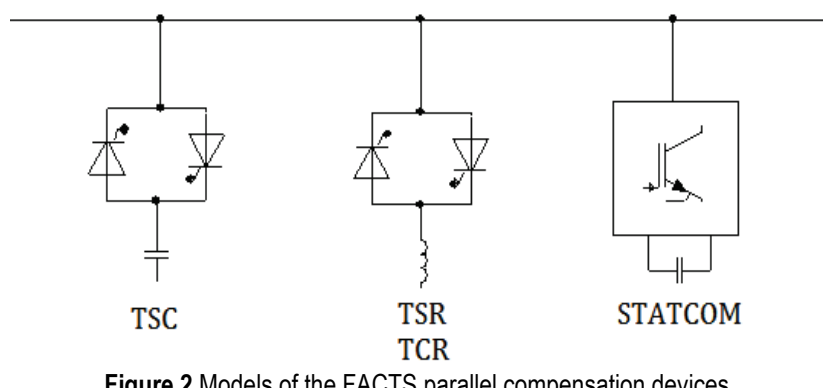

The Active Compensation System or FACTS system can be based on:

- $\quad$ TSC - Thyristor Switched Condenser 
- $\quad$ TSR - Thyristor Switched Reactor

- TCR - Thyristor Controlled Reactor

- $\quad$ STATCOM - Static Synchronous Compensator.

The definition of reactive power follows from the reactive current, which is the difference between the total current $i$ and the active current $i_{a}$, [4]. Reactive current $i_{q}$ is called the reactive or inactive current in sinusoidal conditions and can be modelled with equivalent elements (inductance or capacitance).

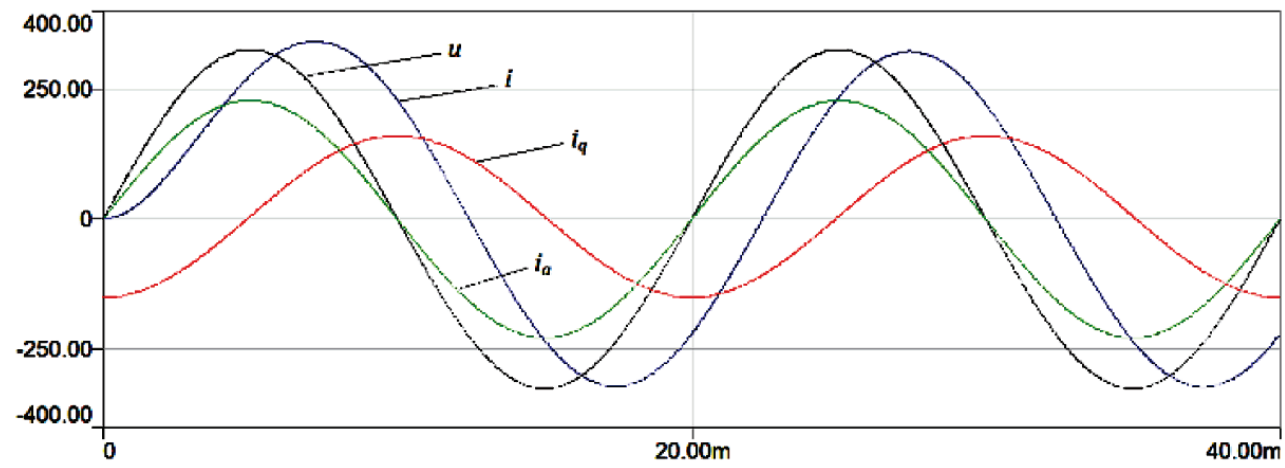

Figure 3 Decomposition on active and reactive current

The product of the voltage $u$ and the current $i$ results in the oscillating power $p$, Fig. 3. At certain moments, the power is negative, indicating that the energy returns back to the source. The product of the voltage $u$ and the active current $i_{\mathrm{a}}$ result in active power $p_{\mathrm{a}}$. Active power $p_{\mathrm{a}}$ oscillates but is always positive. The mean value of the active power $\left(p_{\mathrm{a}}\right)$ by definition is equal to the power $p$. The product of the voltage $u$ and the reactive current $i_{\mathrm{q}}$ results in the power of $u i_{\mathrm{q}}$ with the mean value 0 . However, this size is not a real reactive power.

Time functions do not display voltage-current relations in the best way. Therefore, in Fig. 4, a phasor diagram of voltage $U$ and current $I$ is shown that can be used for the graphic definition of reactive power.

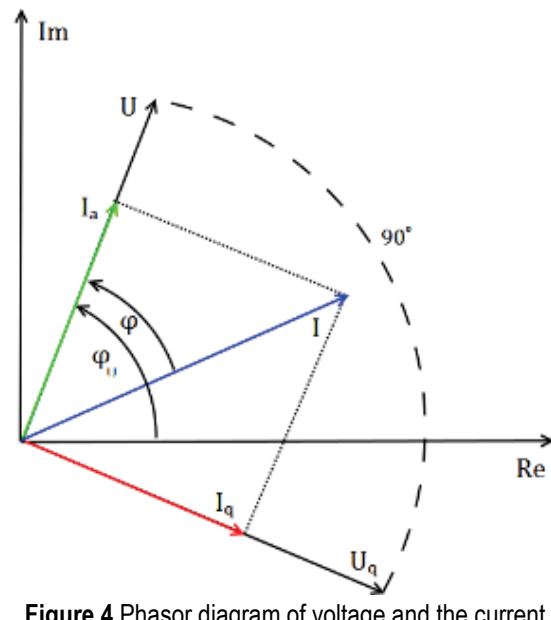

The fictitious voltage required for the definition of reactive power is defined as the original voltage phase rotated for $90^{\circ}$ in the positive or negative direction, depends on the inductive/capacitive character, Fig. 3.

It follows that the reactive power is equal to the product $U$ and $I_{q}$. Phasor $I_{q}$ is equal to $I \cdot \sin \varphi$.

$Q=U_{q} \cdot I_{q}=U \cdot I \cdot \sin \varphi$
Finally, it is necessary to define the apparent power $S=$ $U \cdot I$ :

$$
\begin{aligned}
& U^{2} I^{2}=U^{2} I_{a}^{2}+U^{2} I_{q}^{2} \\
& S^{2}=P^{2}+Q^{2}
\end{aligned}
$$

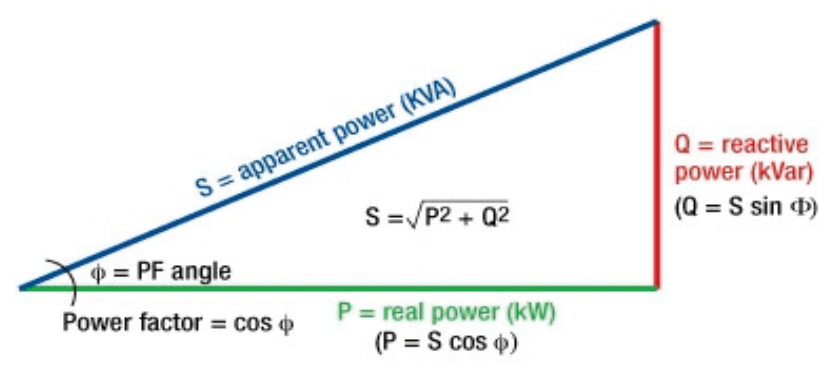

Figure 5 Vector diagram of the relation between the active, reactive and apparent power

The power factor is defined as the ratio of working $P$ and apparent power $S$ which is equal to the cosine angle $\varphi$ between their vectors shown in Fig. 5 .

$\lambda=\frac{P}{S}=\cos \varphi$

It should be noted that the power factor in Eq. (3) is valid if it is for linear load and if the current and voltage is given by the sinusoidal waveform source.

Nonlinear consumption causes distortion of current and voltage. In order to analyse the effect of these distortions, periodic signals can be separated by Fourier's order into the sinusoidal components, a frequency that is a multiple of the basic frequency of the system, [5]. These sine components are called harmonics. The periodic function $f(x)$ defined in the interval $[-L, L]$ is given by:

$$
f(x)=\frac{a_{0}}{2}+\sum_{n=1}^{\infty}\left(a_{n} \cos \frac{n \pi x}{L}+b_{n} \sin \frac{n \pi x}{L}\right)
$$

Where $a_{0}, a_{n}$ and $b_{n}$ is given by: 


$$
\begin{aligned}
& a_{0}=\frac{1}{L} \int_{-L}^{L} f(x) \mathrm{d} x \\
& a_{n}=\frac{1}{L} \int_{-L}^{L} f(x) \cos \frac{n \pi x}{L} \mathrm{~d} x \\
& b_{n}=\frac{1}{L} \int_{-L}^{L} f(x) \sin \frac{n \pi x}{L} \mathrm{~d} x \\
& n \in \mathbb{N}
\end{aligned}
$$

The harmonics most represented in $f(x)$ have the greatest amplitude in relation to the amplitude of the base harmonic, while the lower amplitude harmonics are less represented. In the case of power electronics such as inverters and rectifiers, with the basic harmonic, the most common are the odd harmonics and those harmonics acting on triple frequency of the basic and their multipliers.

The measure used to define the degree of distortion of the sinusoidal signal is called the total harmonic distortion (THD) and is defined as the sum of the squares of all the higher harmonic components and square of the base harmonic signal, [6].

$$
T H D_{f}=\frac{\sqrt{\sum_{i=2}^{n} f_{i}^{2}}}{f_{1}}
$$

where $f_{1}$ is the effective value of the basic harmonic signal, and $f_{i}$ is the effective value of the $i^{\text {th }}$ harmonic signal.

$D F$ (eng. DF - Distortion Factor) is defined as:

$$
D F=\frac{1}{\sqrt{1+T H D^{2}}}
$$

Finally, the general power factor, taking into account current distortions expressed with $T H D_{I}$ and voltage distortions expressed as $T H D_{U}$, is given by:

$$
\lambda=D F \frac{P}{S}=\frac{1}{\sqrt{1+T H D_{U}^{2}}} \frac{1}{\sqrt{1+T H D_{I}^{2}}} \frac{P}{S}
$$

From Eq. (8) it is visible that the power factor is dependent not only on phase shift between current and voltage, but also on the level of harmonic distortion of these two magnitudes.

\subsection{Static Synchronous Compensator}

Static Synchronous Compensator (STATCOM) is connected to the drive in a similar way to SVS, however, its capacitive or inductive current can be operated independently of the AC system voltage. STATCOM is based on a voltage-controlled source derived from power electronics. STATCOM is part of the FACTS family of devices.

STATCOM is typically connected as a support to systems with very low power factor and poor voltage regulation. However, it is also used for other purposes, the most common of which is voltage regulation. DC voltage is used for the voltage source and therefore STATCOM has poor active power control possibility. The ability to control active power can be increased by connecting appropriate energy storage. Reactive power on STATCOM connectors depends on the voltage source amplitude. For example, if the voltage source is higher than the voltage on the connectors, STATCOM generates a reactive current. If the voltage on the connectors is higher than the voltage source, STATCOM absorbs the reactive current.

The STATCOM response time is shorter than the response time of the SVC system, mostly because of the ability of the IGBT to switch the circuit off and on quickly. STATCOM also provides better support for reactive power under low voltage conditions than the SVC, as STATCOM's reactive power decreases linearly with a voltage drop. The current can be kept at nominal value and at low voltage values.

\section{SIMULATION OF THE OPERATION OF THE NON- LINEAR LOAD WITH THE ACTIVE POWER FILTER IN THE PROGRAMME PACKAGE MATLAB SIMULINK}

The MATLAB Simulink program simulated the work of a non-linear consumer, with the aim of analysing the influence of dynamic reactive power regulation using an active filter of power. The model was created according to the theory of current power, which is in short lines, described in the previous chapter. Fig. 6 shows the simulation model of dynamic compensation of reactive power for nonlinear consumer in MATLAB Simulink. The source of power supply is represented by a three-phase source of sinusoidal voltage, the effective value of the 400 $\mathrm{V}$, the phase winding is a star, while the star point is directly connected to the potential of the earth (zero potential), the frequency of $50 \mathrm{~Hz}$, with the initial phase and the zero stage and the phase shift of $120^{\circ}$.

The simulation model also includes a block which is predicted to make model of the phase conductor impedance to the point PCC (Point of Common Coupling), which in fact represents a point of the consumer's connection to a low-voltage three-phase source. Impedance of phase conductors from three-phase power supply to PCC point, is presented in the MATLAB Simulink environment of inductively-resistant branches ("Series RL branch") with active resistance per phase of $0,01 \Omega$ and inductance of 6 $\mu \mathrm{H}$. At the point of PCC, that impedance block is connected to ideal three-phase measurement, phase voltages and currents. At the output of this block phase voltages and current can be obtained, as indicated in Fig. 7 with $U_{\mathrm{c}}$ and $I_{\mathrm{c}}$. At the PCC point, there are also nonlinear loads subsystems, and the active power filter ("Shunt APF"). At the output of the subsystem of the nonlinear load there is a block labelled as I load, whose role is to send the measured values of the phase currents of the consumer ("load") to the corresponding block in the developed subsystem scheme representing the non-linear consumer. The nonlinear three phase consumer is modelled in phase with a series of RL branches, active phase resistance of 6 $\Omega$ and inductance of $8 \mathrm{mH}$, phase $\mathrm{b}$, with branch of parallel connection of active resistance of $4 \Omega$ and capacitance 50 $\mu \mathrm{F}$, and phase c with an active resistance of $3 \Omega$. Phase loads are related to the voltage source through the diode bridges, which, besides the voltage asymmetry and the 
current, due to the unstimulated loads per phase, add additional distortion of voltage and current of the consumer. Diode bridges have the role of rectifiers, and form at the output of pulse waveforms of voltage and current.

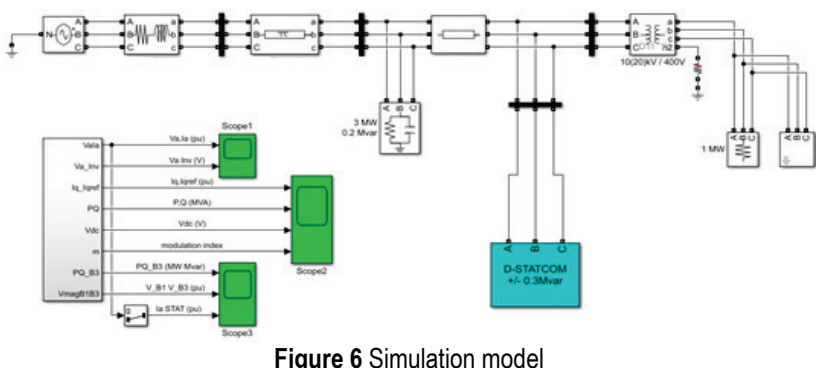

Fig. 7 also shows a subsystem representing the active power filter (Shunt APF). The main role of the active filter of power is to form a set of three phase compensating currents, which are realized by an invertor bridge, realized by the use of IGBT transistors and diodes as switching elements. The inverting voltage of the invertor bridge is obtained by applying two $400 \mu \mathrm{F}$ condenser sections, which represent the energy source for the formation of compensating phase currents at the output of the inverter. These currents are injected at the PCCpoint.

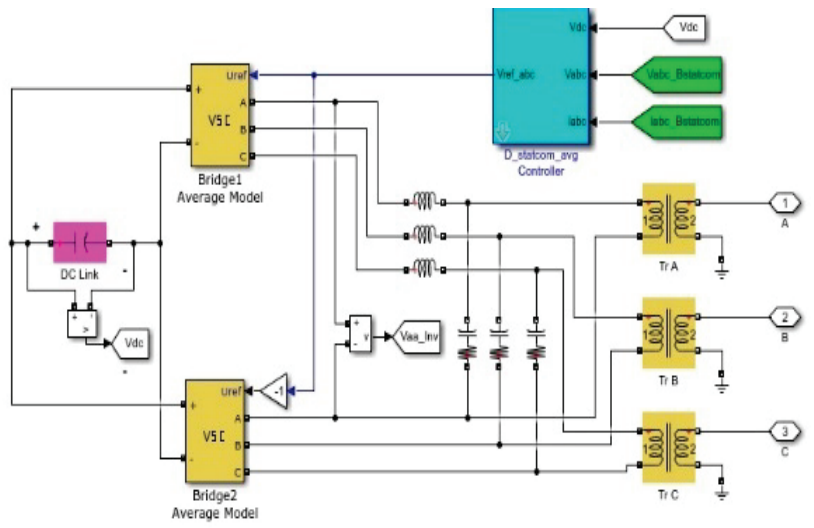

Figure 7 Simulation sub-model

The role of PI controller is to reduce active power losses caused by DC voltage oscillations. Fig. 7 also shows a block for calculating the necessary active and reactive power by the current power theory which needs to be compensated. Based on these power forms, the abovementioned block calculates the appropriate compensating current. These currents serve as reference and then compare with the values of the measured phase currents on the consumer. The comparison of these two currents is performed by applying a hysteresis controller and based on this comparison, the control currents that are led on the control gate (Gate), the IGBT transistor are generated, which controls the periods of ignition and extinguishing of certain switching elements for the purpose of generating and realizing injecting compensating phase currents at the PCC point. The final result is that in this way the injected currents at the PCC point, from the aspect of the input three-phase power supply, withdraw symmetrical, unbalanced phase currents, which was the goal of this simulation.

\section{ANALYSIS OF THE RESULTS OF SIMULATION OF THE REACTIVE POWER DYNAMIC COMPENSATION}

Fig. 8 shows the temporal changes of the phase voltages of the power supply sources THD analyses were performed on the output curves from the simulation model and one of them is presented in Fig. 9.
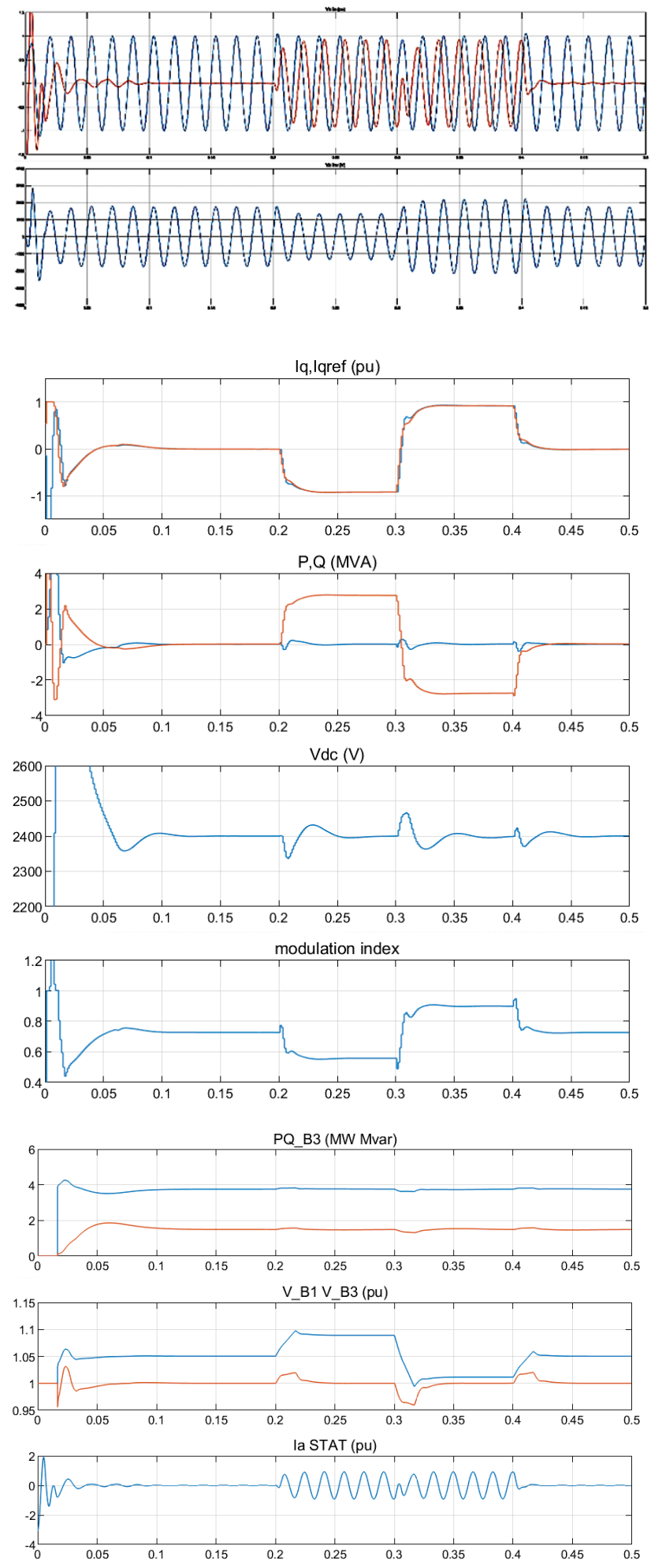

Figure 8 Output curves from the simulation model 


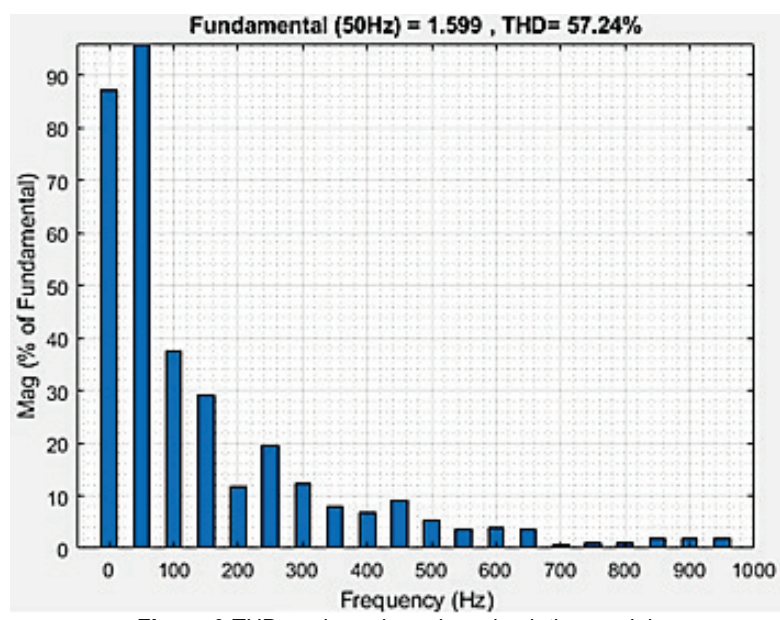

Figure 9 THD analyses based on simulation model

\section{SUBSTATION DESIGN RECOMMENDATION}

Electric-traction substation (EVP) $110 / 25 \mathrm{kV}$ installed power $2 \times 7,5 \mathrm{MVA}$ is a separate plant. It consists of an external $110 \mathrm{kV}$ plant and a $25 \mathrm{kV}$ plant located in the building. It has been in operation since May 1987.

Electric traction vehicles (Locomotives) with electrified alternating systems of $25 \mathrm{kV}, 50 \mathrm{~Hz}$, are beside active, significant consumers of reactive energy, which causes significant costs in the electricity cost.

One of the basic indicators of the needs for building a compensation facility is data on monthly used active and reactive power from the HOPS network. Those measurements indicate that in EVP it is desirable to construct a reactive energy compensation plant. This would reduce the cost of electricity taken over from the HOPS network for electric traction needs, and indirectly increase the available substation power, thereby improving the voltage potential of the contact grid.

Analysing the data on the amounts of capacitive and inductive reactive energy for EVP $110 / 25 \mathrm{kV}$, it has been observed that during the day there are periods in which there is no train's traffic. This also means that there is no main source of inductive reactive energy and then a compensation value of approximately equal to 0 is needed (there is always a small amount to be compensated due to the capacitive reactive energy generated by the contact line conductors and the inductive reactive energy generated by the energy transformer). Fixed compensation, as it is installed in other compensation facilities, would in such periods provide almost the full amount of installed power compensation, which would be a huge expense due to the method of charging and the capacitive components of the reactive power. Thus, the Fixed Compensation solution no longer satisfies, and the conceptual technical compensation solution that is dynamically adapted to the network conditions is created and accepted. A new technical solution is base point for the construction of this plant, which will also be the first plant with such compensation.

The reactive power plant consists of a fixed part, i.e. condenser units and three-stage inductive filter: 964, 643 and $482 \mathrm{mH}$ and a variable (static) part, i.e. adaptive transformer $25 / 0,4 \mathrm{kV}$ and the required number of static inverters rated power $225 \mathrm{kVAr}$.

Table 1 Possible installed power of the compensation plant

\begin{tabular}{|l|c|c|c|}
\hline Installed Power of fixed compensation, kVAr (at 26,5 kV Voltage) & 463 & 695 & 927 \\
\hline Number of Capacitor units & 4 & $4+4$ & 8 \\
\hline Number of Capacitor units in parallel, m & 2 & $2+2$ & 4 \\
\hline Number of Capacitor units in the series, $\mathrm{n}$ & 2 & 2 & 2 \\
\hline Installed Power of variable (static) compensation, kVAr & \pm 450 & \pm 675 & \pm 900 \\
\hline Number of cabinets of variable (static) compensation & 2 & 3 & 4 \\
\hline Total (possible) compensation power, kVAr & $\mathbf{9 1 3}$ & $\mathbf{1 . 3 7 0}$ & $\mathbf{1 . 8 2 7}$ \\
\hline
\end{tabular}

For the installed fixed power compensation $695 \mathrm{kVAr}$, there are 4 condenser units per $178 \mathrm{kVAr}$ and 4 condenser units per $89 \mathrm{kVAr}$, and for all other possible installed capacities are used $178 \mathrm{kVAr}$ capacitors.

The static converter is physically engineered as a cabinet where energy modules are housed as separate modular circuits.

The converter consists of two parallel four-quadrant converters (4QC).

The latest technological knowledge has been applied in the inverter version:

- IGBT switches

- Multi-processor control system with digital signal controller

- Monitoring and diagnostics system.

IGBT switches work with a relatively high switching frequency, and the transfer of control signals to the switches by means of a fibre optic has greatly increased the resistance on interference.

Multiprocessing management system is implemented by modular hardware support. Its main function is generating control pulses for IGBT switches. In addition, it is tailored to the adaptation of the measured signals, the protection of devices and circuits is proven, and it is managed by sequential tasks and supports the monitoring and diagnostic system, which enables easy monitoring and monitoring of the device during operation.

The converter is mechanically constructed as a cabinet in which semiconductor circuits and condenser battery assemblies are housed as separate power modules. Each semiconductor circuit has its own coolant, which ensures the cooling of semiconductor modules. The cooling bodies are located in the air ducts and forced by means of two fans. At the bottom of the cabinet there are input chokes, metaloxide varistors, switching contactor and main contactor and auxiliary single phase voltage stabilizer. The control electronics of the device are located on the cabinet door, where the signalling, the mushroom switch for the emergency off and the LCD display are located.

Fan motors with cooling fan for cooling units of the inverter are powered by auxiliary single-phase voltage $220 \mathrm{~V}, 50 \mathrm{~Hz}$ over a magnetic voltage stabilizer, which is significantly increased resistance to voltage distortion at 25 $\mathrm{kV}$ side network. 


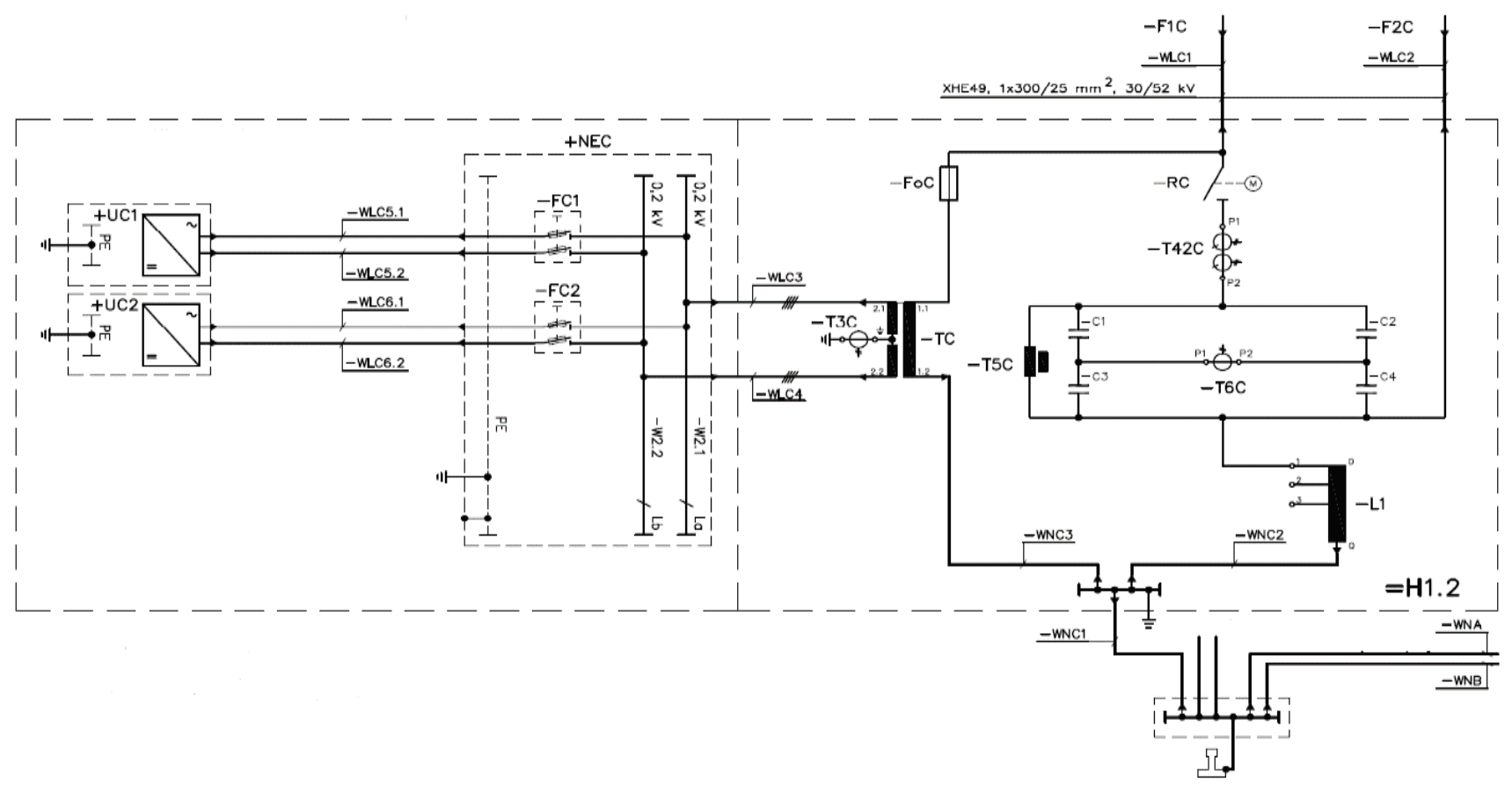

Figure 10 Single line diagram of reactive power compensation facilitty

\begin{tabular}{|c|l|c|}
\hline \multicolumn{2}{|c}{ Table 2 Converter Technical data } & $225 \mathrm{kVAr}$ \\
\hline \multirow{4}{*}{ Power } & Nominal Power & $225 \mathrm{kVAr}$ \\
\cline { 2 - 3 } & Power, InputVoltage above 360V & $(175 \div 225) \mathrm{kVAr}$ \\
\cline { 2 - 3 } & Power, Input Voltage $(280 \div 360) \mathrm{V}$ & $400 \mathrm{~V}$ a.c. \\
\hline \multirow{5}{*}{ Input Voltage } & Rated Input Voltage, effective value & $(280 \div 480) \mathrm{V} \mathrm{a.c.}$ \\
\cline { 2 - 3 } & Permissible Input Voltage deviation, effective value & $50 \mathrm{~Hz}$ \\
\cline { 2 - 3 } & Input Voltage rated Frequency & $(48 \div 52) \mathrm{Hz}$ \\
\cline { 2 - 3 } & Permissible Input Voltage Frequency deviation & $562,5 \mathrm{~A}$ \\
\hline \multirow{3}{*}{ Current } & Rated Current, effective value & $960 \mathrm{~A}$ \\
\cline { 2 - 3 } & Max. Current, peak value & $625 \mathrm{~A}$ \\
\cline { 2 - 3 } & Current limit, effective value & \\
\hline
\end{tabular}

Inverter controllers, DC converters, voltage transducers and current inverters are powered from a stable $110 \mathrm{~V}$ DC source for the entire plant.

\section{CONVERTER FOR DYNAMIC REACTIVE POWER COMPENSATION}

The dynamic reactive power compensation converter is designed for installation in the power supply substations $25 \mathrm{kV}, 50 \mathrm{~Hz}$ and the inverter rated power is $225 \mathrm{kVAr}$. One or more inverters can be installed individually in the electric traction substations or combined with fixed compensation devices. There are two inverters installed in the electrical substation. Figure 10 shows the single-pole diagram of the complete plant for the compensation of reactive energy in the electric substation. The embedded inverters are in the scheme labelled with -UC1 and -UC2 and are connected in parallel to a single-phase adaptive transformer rated power of $1000 \mathrm{kVA}$ and a transmission ratio of $25 / 0,4 \mathrm{kV}$, which is shown in the scheme with -TC. Since the ability to increase the compensation power by the addition of two inverters and additional capacitor batteries has been left open, in Fig. 10, two more inverters can be added with the -UC3 and-UC4, which can be subsequently added.

Fig. 11 shows the block diagram of the inverter. The inverter is connected to the secondary side of a singlephase adaptive transformer with a nominal power of 1000 $\mathrm{kVA}$ and a transmission ratio of $25 / 0,4 \mathrm{kV}$.
The secondary winding of the transformer is made of two parts with a drawn centre point that connects to the ground of the entire plant (Fig. 10). The metal-oxide varistors connected to the surge arrester are connected between the transformer and earthing terminals.

The inverter power circuits are connected to the secondary transformer voltage by the pre-assembly bust circuit.

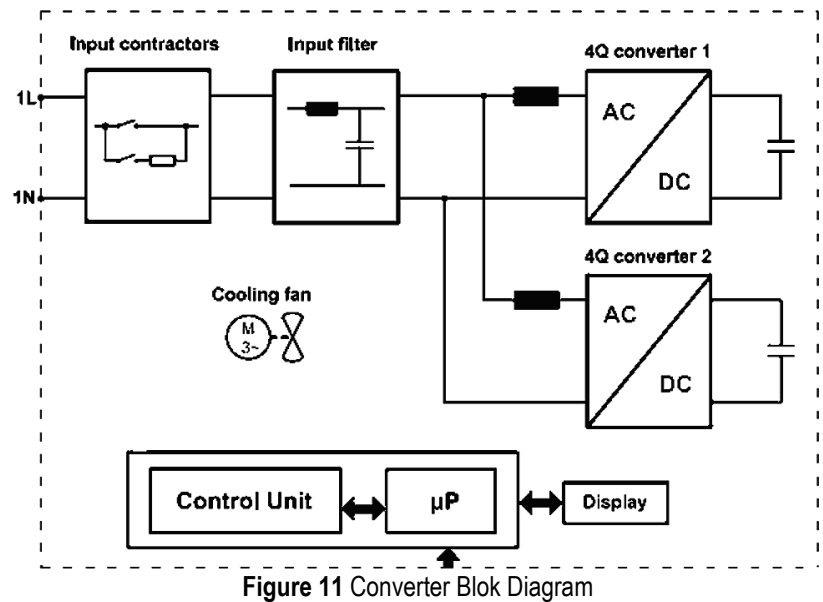

The main part of the inverter consists of two singlephase routers. Each router is connected to the secondary side of the transformer via a choke, and on the output side of the router there is a capacitor battery (DC circle). 
In addition to the power supply, the converter connects to the auxiliary power supply in the plant. The first one auxiliary single phase voltage is $230 \mathrm{~V}, 50 \mathrm{~Hz}$. This voltage through the magnetic stabilizer is powered by two singlephase motors with fans that serve to cool the coolant with semiconductor switches. Voltage stabilization has significantly increased the resistance to voltage distortion on the $25 \mathrm{kV}$ side of the grid. The second auxiliary voltage is the DC voltage $110 \mathrm{~V}$ which is powered by contactors, and through DC controllers of control electronics, auxiliary relays, display and signal lights.

Inverters are also supplied with high voltage signal meters. Voltage signal is transmitted to the $25 \mathrm{kV}$ side via the voltage measuring transformer, and through the current measuring transformers the signal of the total current of the electric traction substation at the $25 \mathrm{kV}$ side. The aforementioned signals are processed by the control electronics and based on them, the required power for dynamic compensation is determined.

The latest technological knowledge has been applied in the inverter version: IGBT switches are used, in the control electronics a multi-processor digital system based on the processor for the processing of the signal with a moving point, a system of protection, monitoring and diagnostics was introduced, and multilayer printing technology was used with the use of environmentally friendly materials. The IGBT switches work at a frequency of $2 \mathrm{kHz}$, and the transfer of control signal to the switches is performed with increased resistance of the device. The main function of multiprocessor digital control system is generating control pulses for IGBT router switches. In addition, the management system is used to customize measured signals, device and circuit protection, sequential task management, and support for monitoring and diagnostics, enabling easy monitoring and monitoring of device performance. Parallel connected inverters are interconnected by a CAN communication bus.

The converter is mechanically constructed as a cabinet in which semiconductor circuits and condenser battery assemblies are housed as separate power modules. Each semiconductor circuit has its own coolant, which ensures the cooling of semiconductor modules. The cooling bodies are located in the air ducts and forced by means of two fans.

\section{ANALYSES DURING OPERATION OF REACTIVE POWER COMPENSATION FACILITTY}

The analysis of the operation of the reactive energy compensation plant in the EVP $110 / 25 \mathrm{kV}$ during the operation to determine the fulfilment of the basic purpose of the plant was performed in two parts. The first part included measurements at the plant and later analysis of the data collected, while the second part included analysis of the accounting data.

The current and voltage measurements were performed in the period of 17.01.2018. (Wednesday) until 29.01.2018. (Monday) and from 21.02.2018. (Wednesday) until 7 March 2018. (Wednesday). The current voltage values at the $25 \mathrm{kV}$ bus and on the capacitors of the fixed part of the KJE plant are measured, and the total current of both transformer fields, then the current of the total KJE and the current of the fixed part KJE.

Based on the current values of the specified currents and voltages, the average, minimum and maximum values are calculated for 5 minutes. In addition to the current and voltage for each 5 minutes' period, mean, minimum and maximum values of working, reactive and apparent power are calculated. At all times, the KJE plant was in operation. The measurement results are used for more precise adjustment of static inverter operation.

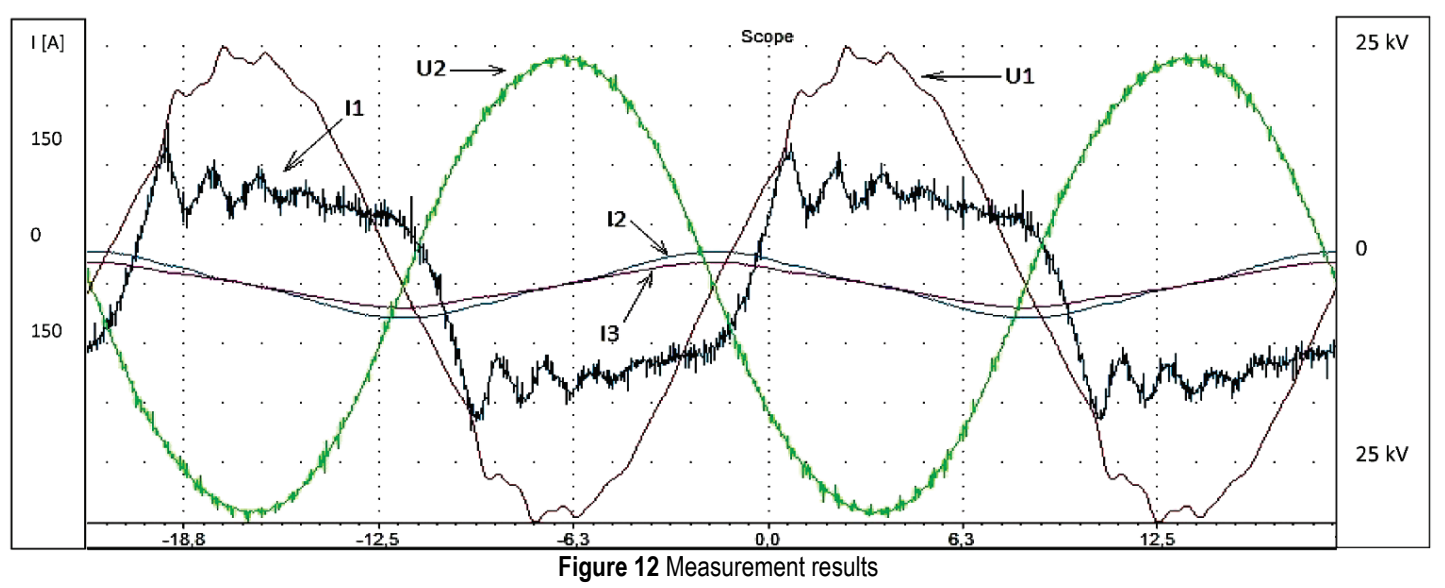

Fig. 12 shows that the current of the fixed part of the KJE plant (I3) is different from the total current KJE (I2). From this it can be concluded that the total current of KJE apart from the fixed part of the plant is contributed by the static inverters.

During the measuring period, the values of the contact voltage (U1) voltage values did not exceed the permissible limits (from a minimum of $19 \mathrm{kV}$ to a maximum of 27,5 $\mathrm{kV}$ ) and it can be concluded that during this period the plant was in normal operation. It can also be concluded that during the measuring period there was no negative impact of the KJE plant on EVP 110/25 kV work.
Based on the measured voltage and current values of the contact network (U1 and I1), graphs of the working and reactive power during the measuring period were prepared. From the graphs it has been noticed that the reactive power is compensated for the most times except the moments when the required reactive power value is greater than the nominal power of the installed plant for KJE. Those moments when the required amount of reactive power exceeds the installed power of the KJE plant are rare and short-timed and there is no need to further increase the installed power. 
According to the electricity accounts for the $110 / 25 \mathrm{kV}$ EVP in the last 2017, the monthly fee for excess energy taken over was slightly more than HRK $31,000.00$, i.e. at the level of the year this amounted to slightly more than HRK 380,000.00. The experimental operation of the reactive power plant was carried out in the period 29.12.2017. (Friday) until 28.02.2018. (Wednesday). In Tab. 3, there are measured data for active and reactive energy consumption for January and February 2018, and in Tab. 4, the monthly costs for overreached reactive energy.

Tabele 3 Data from the trial operation for January and February

\begin{tabular}{|c|c|c|}
\hline Month & $\begin{array}{c}\text { Total consumed active } \\
\text { energy, } \mathrm{kWh}\end{array}$ & $\begin{array}{c}\text { Over-consumed reactive } \\
\text { energy, kVArh }\end{array}$ \\
\hline January & 588.291 & $5.348,97$ \\
\hline February & 559.009 & $7.807,03$ \\
\hline Total & $\mathbf{1 . 1 4 7 . 3 0 0}$ & $\mathbf{1 3 . 1 5 6 , 0 0}$ \\
\hline
\end{tabular}

Tabele 4 The costs of trial operation for January and February

\begin{tabular}{|c|c|}
\hline Month & Over-consumed reactive energy fee, $\mathrm{HRK}^{*}$ \\
\hline January & 855,83 \\
\hline February & $1.248,13$ \\
\hline Total & $\mathbf{2 . 1 0 3 , 9 6}$ \\
\hline * exchange rate: EUR $=7,426371 \mathrm{HRK}$ (source: $\mathrm{https} / /$ www $\mathrm{hnb} \cdot \mathrm{hr}$ \\
\hline
\end{tabular}

temeljne-funkcije/monetarna-politika/tecajna-lista/tecajna-lista)

During this period, the expense for overreached energy was recorded in the amount of 855,83 HRK for January and 1.248,13 HRK for February. Compared to the same period in the previous year, the cost of excessive energy during the experimental operation of the reactive power plant was $4 \%$ of the cost in 2017 and based on the collected data it can be concluded that the reactive power compensation plant meets the intended purpose.

\section{CONCLUSION}

If we compare the costs for excessive reactive energy for January and February 2017, January and February 2018, we can see that total costs have drastically reduced (up to 26 times). The surplus of overreached energy costs for the month of February is higher than in January, since only one inverter was in operation in the period from February 7 to February 12 in the part of the plant for dynamic compensation of the reactive energy, and thus the capacitive component of the reactive energy is higher.

The facility for dynamic compensation of reactive energy is acceptable if it is demonstrated that at the monthly level the excess overreached reactive energy does not exceed $20 \%$ of the costs for energy before construction of that part of the plant for dynamic reactive energy compensation. Given the presented results and the HOPS Energy Consumption Bill for January and February for 2018 , it can be verified that the costs of excessive energy consumed on a monthly basis are less than $5 \%$ of the costs for excess energy taken over before the construction of the plant for variable reactive energy compensation, which has proved that the newly constructed dynamic compensating plant is acceptable.

\section{REFERENCES}

[1] See https://www.hep.hr/ods/korisnici/poduzetnistvo/tarifnimodeli-47/47; https://www.hep.hr/ods/korisnici/poduzetnistvo/tarifnestavke-cijene-161/161

[2] Benabid, R., Boudour, M., \& Abido, M. A. (2009). Optimal location and setting of SVC and TCSC devices using nondominated sorting Particle Swarm Optimization. Electric Power Systems Research, 79, 1668-1677. https://doi.org/10.1016/j.epsr.2009.07.004

[3] Aghaei, J., Gitizadeh, M., \& Kaji, M. (2012). Placement and operation strategy of FACTS devices using optimal continuous power flow. Scientialranica, 19(6), 1683-1690. https://doi.org/10.1016/j.scient.2012.04.021

[4] Ghahremani, E. \& Kamwa, I. (2013). Optimal placement of multiple-type FACTS devices to maximize power system loadability using a generic graphical user interface. IEEE Trans Power Syst, 28(2), 764-778. https://doi.org/10.1109/TPWRS.2012.2210253

[5] Deihimi, A. \& Javaheri, H. (2010). A fuzzy multi-objective multi-case genetic-based optimization for allocation of FACTS devices to improve system static security, power loss and transmission line voltage profiles. International Review of Electrical Engineering (IREE), 5(4), 1616-1626. https://doi.org/10.1109/ICMET.2010.5598425

[6] Singh, B., Mukherjee, V., \& Tiwari, P. (2015). A survey on impact assessment of DG and FACTS controllers in power systems. Renew. Sustain. Energy Rev, 42, 846-882. https://doi.org/10.1016/j.rser.2014.10.057

[7] Moradi, M. H. \& Abedini, M. (2012). A combination of genetic algorithm and particle swarm optimization for optimal DG location and sizing in distribution systems. Int. J. Electr. Power Energy Syst, 34, 66-74. https://doi.org/10.1016/j.jiepes.2011.08.023

[8] Devi, S. \& Geethanjali, M. (2014). Optimal location and sizing determination of Distributed Generation and DSTATCOM using Particle Swarm Optimization algorithm, Int. J. Electr. Power Energy Syst, 62, 562-570. https://doi.org/10.1016/j.jiepes.2014.05.015

\section{Contact information:}

Josip PAVLEKA, B.Sc

HEP-Distribution System Operator Ltd.,

Ulica grada Vukovara 37, 10000 Zagreb, Croatia

E-mail: josip.pavleka@gmail.com

Srete NIKOLOVSKI, PhD, Full Professor

Faculty of Electrical Engineering, Computer Science and Information

Technology Osijek, Kneza Trpimira 2b, 31000 Osijek, Croatia

E-mail: srete.nikolovski@ferit.hr

Anton MARUŠı́́, B.Sc

HEP-Distribution System Operator Ltd.,

Ulica grada Vukovara 37, 10000 Zagreb, Croatia

E-mail: anton.marusic@hep.hr 